from elevating it into a moral principle. For those of us who do take an interest in these matters, however, recent events - the national curriculum debate in particular-must surely prompt us to reflection on how we can make more effective interventions.

My own feeling is that we need to start talking more concretely about what we are for as well as what we are against (e.g. grammar drills and standard English in the playground). Researching Verbal hygiene convinced me that the main obstacle to our making our views 'heard' beyond the boundaries of our discipline is the lay perception of us as unreconstructed relativists with no values or standards at all - we are seen as a strange and mealy-mouthed group of experts for whom ways of using language can only be more or less 'acceptable' or 'appropriate', never 'good' or 'bad'. (Milroy finds my discussion of linguists' language confused, and perhaps it is: but part of my point is simply that we have sometimes given a misleading impression of ourselves by not using plain words.)

Linguists do not lack the hygienic impulse, as our own writings show. We acknowledge not only the beauty and intricacy of human languages but also degrees of skill and artistry in the use of them (qualities which are not however confined to 'polite' letters). We criticise departures from certain standards of clarity and correctness in one another's use of languagewitness Milroy's remarks on my spelling. Why should we suppress our value-judgements, or dress them up in language that is likely to be misunderstood? Better, surely, to show how evaluation can be made more accountable to knowledge and to reason. Verbal hygiene is, among other things, an expression of my hope that in future, through the efforts of linguists and nonlinguists alike, we will have a form of public discourse on language which is informed and rational, as well as passionate.

Deborah CAmeron Programme in Literary Linguistics, Strathclyde University, Glasgow G1 1XH, Scotland d.j.cameron@strath.ac.uk

\title{
Reply to Deborah Cameron on Verbal hygiene
}

\section{James Milroy}

I greatly liked Verbal hygiene, and I couldn't agree more with most of what Cameron says in her reply to my review. Linguists have some responsibility to get involved in public affairs when they have something useful to 
contribute. If we confine ourselves only to what they have published on prescriptivism, however, much of what they have said is not useful because it does not make contact with strongly held public attitudes to language. Missionary efforts, while advocating non-prescriptivism, are in themselves prescriptive. However, it should be recognized that many linguists have served on public committees, such as Kingman and Cox, and have attempted to communicate in a moderate and responsible way. They can't help it if politicians treat their reasonable suggestions in such a contemptuous way.

I have one main objection to Cameron's view and that is her view of the institutional nature of 'linguistics', and it is clear from her comments that she knows this. Linguistics, in my view, is not 'an institution with the power to license bona fide practitioners.' The assessment of doctoral thesis, selection of job candidates and reviewing of manuscripts for publication, are all activities carried out by individuals. The effect of the 'canons' of linguistics on these activities is both indirect and highly variable, depending on the immediate needs of particular departments and universities. There is great variety, because of the variety of individual teachers and specialisms. The only strongly ideologically-based job factory that I know of is in the United States, at MIT, and its graduates are unlikely to get their hands dirty by contributing to educational debates.In a sense they are not in the same subject as Cameron and I are. In fact the general tolerance of 'linguistics' as a Broad Church is shown by precisely the case she mentions - that of John Honey, whose pamphlet The language trap has been widely referred to and discussed, and who has since published on the subject of British accents.

Cameron says she is not attacking individuals, but the institutional canons of the discipline.' If in fact she means the centrality of Saussurean structuralism or something similar, then I would agree that this is a proper subject for discussion, but I think that such a discussion would have little immediate relevance to debates outside of linguistics, since no one else either knows or cares about it. But I couldn't agree more with her more general point. We certainly should 'reconsider some of the things that we now consider to be self-evident' within linguistic theory and method.

I sympathize greatly with the points she makes in her last paragraph. Perhaps it is an effect of old age, but, sadly, I'm pessimistic about the possibility of a well informed public discourse taking place in the foreseeable future. I hope nonetheless it will come about. 